\title{
Sobre a comiseração em Spinoza
}

\author{
IGOR ALVES DE MELO *
} * Doutorando em Filosofia
pelo PPGF-UFRJ
RESUMO O objetivo deste artigo é interpretar o afeto da comiseração segundo a teoria dos afetos de Spinoza (Ética III e IV). Para tal, distingue-se o conteúdo prático da benevolência de acordo com a origem, natureza e força dos afetos. Por fim, examina-se em que sentido a benevolência proveniente da comiseração seria uma tristeza, enquanto a que provém da piedade seria uma alegria.

PALAVRAS-ChaVe Comiseração. Benevolência. Alegria. Tristeza. Teoria dos afetos.

\section{INTRODUÇÃO}

Spinoza define o afeto da comiseração (commiseratio) como uma tristeza (tristitia) proveniente da desgraça alheia daquilo que amamos ou que nos é semelhante. Em contrapartida, define a piedade (pietas) ${ }^{1}$ como o desejo de fazer o bem de quem vive sob a condução da razão. ${ }^{2}$ A causa da comiseração é a tristeza, enquanto a causa da piedade é a alegria (laetitia). Spinoza só utilizada o termo 'benevolência' (benevolentia) quando se refere à comiseração, embora empregue o mesmo significado prático (desejo de fazer o bem) quando se refere à piedade. Posto isso, que distinção haveria entre a benevolência proveniente da comiseração e a benevolência que provém da piedade? De que maneira esses afetos definem o conteúdo prático de suas ações? Pretendo, pois, examinar esse jogo afetivo de acordo com a teoria da imitação dos afetos

1 Como veremos, o que Spinoza chama de piedade difere toto coelo do sentido dado pela moral cristã na tradição da filosofia ocidental.

2 A seguir, deve ficar claro que a concepção de razão em Spinoza não se opõe aos afetos, diferentemente, por exemplo, da concepção dualista de Descartes. 
(E III) e o conceito spinozano (muito particular na história da filosofia moderna) de razão ou conhecimento de $2^{\circ}$ gênero (E IV).

\section{PIEDADE VERSUS COMISERAÇÃo}

No escólio da E III 22,3 Spinoza define o afeto da comiseração como "a tristeza originada da desgraça alheia”, e mais adiante, na 18 a definição dos afetos da parte III, complementa: “A comiseração é uma tristeza acompanhada da ideia de um mal que atingiu um outro que imaginamos ser nosso semelhante". A comiseração é uma paixão que tem como origem a imitação do afeto de tristeza daquilo que amamos ou nos é semelhante. É o que diz o enunciado da E III 21: “Quem imagina que aquilo que ama é afetado de alegria ou de tristeza será igualmente afetado de alegria ou de tristeza; e um outro desses afetos será maior ou menor no amante à medida que, respectivamente, for maior ou menor na coisa amada." Quando uma pessoa é tomada de comiseração por aquilo que ama, podemos dizer que ela ama a causa de sua tristeza. Pois como diz o segundo corolário da E III 27, "Se uma coisa nos causa comiseração, não é porque sua desgraça nos afeta de tristeza que podemos odiá-la.” Além disso, também pode ser causa de nossa tristeza aquilo que apenas nos é semelhante, isto é, a coisa pela qual não fomos anteriormente afetados por qualquer afeto. Nesse sentido, a demonstração da E III 27 elucida a dinâmica da imitação dos afetos à qual recorro para compreender o significado da comiseração em Spinoza:

As imagens das coisas são afecções do corpo humano, cujas ideias representam os corpos exteriores como presentes a nós (pelo esc. da prop. 17 da P. 2), isto é (pela prop. 16 da P.2), cujas ideias envolvem a natureza de nosso corpo e, ao mesmo tempo, a natureza presente de um corpo exterior. Assim, se a natureza de um corpo exterior é semelhante à do nosso corpo, então a ideia do corpo exterior que imaginamos envolverá uma afecção de nosso corpo semelhante à do corpo exterior. Consequentemente, se imaginamos que alguém semelhante a nós é afetado de algum afeto, essa imaginação exprimirá uma afecção de nosso corpo semelhante àquele afeto. Portanto, por imaginarmos que uma coisa semelhante a nós é afetada de algum afeto, seremos afetados de um afeto semelhante ao seu.

3 Utilizo as siglas convencionais para citar Spinoza: primeiro a referência geométrica (enunciado da proposição, escólio, demonstração, definição, capítulo ou apêndice), depois o nome da obra (Ética, E) e sua respectiva parte (I, II, III, IV ou V) e, por último, o número da proposição. 
Com efeito, somos afetados de alegria ou de tristeza de acordo com a ideia que formamos de uma causa exterior, e essa ideia é uma imagem que envolve tanto a nossa natureza quanto a natureza desse corpo exterior. Quando somos afetados pela comiseração, por exemplo, imaginamos as afecções do corpo que nos afeta pela condição de semelhança entre a natureza do nosso corpo e a natureza de um corpo exterior. E se há essa semelhança, então a afecção do nosso corpo será semelhante, assim como a ideia do corpo exterior que imaginamos. Pelo escólio da E III 13, podemos compreender, agora, a dinâmica dos afetos de amor e ódio no âmbito da dinâmica de imitação dos afetos:

O amor nada mais é do que a alegria, acompanhada da ideia de uma causa exterior, e o ódio nada mais é do que a tristeza, acompanhada da ideia de uma causa exterior. Vemos, além disso, que aquele que ama esforça-se, necessariamente, por ter presente e conservar a coisa que ama. E, contrariamente, aquele que odeia esforça-se por afastar e destruir a coisa que odeia.

Essa dinâmica esclarece o próprio movimento do conatus (o esforço pelo qual o homem se esforça por perseverar em seu ser). Então, quando somos afetados de tristeza pela comiseração, nosso conatus é logo determinado a afastar ou destruir a causa dessa tristeza. É o que nos diz o terceiro corolário da E III 27: “Nós nos esforçaremos, tanto quanto pudermos, por livrar de sua desgraça uma coisa que nos causa comiseração.” E Spinoza prossegue na demonstração do mesmo corolário:

Aquilo que afeta de tristeza uma coisa que nos causa comiseração, afeta-nos, igualmente, de uma tristeza semelhante (pela prop. prec.). Consequentemente, nós nos esforçaremos por conjeturar tudo o que exclui a existência dessa coisa, ou seja, o que a destrói (pela prop. 13), isto é (pelo esc. da prop. 9), seremos tomados pelo apetite de destruí-la, ou seja, estaremos determinados a destruí-la e estaremos, assim, por livrar de sua desgraça uma coisa que nos causa comiseração.

Começa a ficar claro, assim, por que, para Spinoza, "A comiseração, no homem que vive sob a condução da razão é, em si, má e inútil.” (E IV 50). Nesse sentido, o corolário da mesma proposição complementa: “o homem que vive pelo ditame da razão se esforça, tanto quanto pode, por não ser tocado pela comiseração.” Enquanto o conatus do homem que vive sob os ditames da servidão naturalmente o conduz a livrar da desgraça a coisa que lhe causa comiseração e, com isso, eliminar a causa da tristeza, o conatus do tipo "homem livre” o conduz a não ser sequer afetado pela comiseração, pois a tristeza seria, por si mesma, má e inútil. Dessa maneira, o homem conduzido 
pela comiseração padece em detrimento de uma causa exterior, a saber, aquilo que ama ou que lhe é semelhante.

Antes de prosseguir com esse ponto, é necessário examinar, ainda que brevemente, a própria dinâmica do conatus em sua estrita relação com os afetos primários de alegria e tristeza. De acordo com o escólio da E III 11, a alegria aumenta ou estimula nossa potência de agir, ou seja, ela é a passagem de uma perfeição menor para uma perfeição maior. Contrariamente, a tristeza diminui ou refreia nossa potência de agir, ou seja, é a passagem de uma perfeição maior para uma perfeição menor. Além disso, segundo o mesmo escólio, a alegria pode ser concebida como excitação (titillatio) ou contentamento (hilaritas), e a tristeza, em dor (dolor) e melancolia (melancholia). A excitação e a dor ocorrem quando uma parte do nosso corpo - ou algumas de suas partes - é mais afetada do que as outras, ou seja, quando as partes do nosso corpo são afetadas de forma desigual. O contentamento e a melancolia, ao contrário, ocorrem quando todas as partes do corpo são igualmente afetadas. Em atenção a essa tese de Spinoza, vale observar também o que nos diz o enunciado da E IV 41: "A alegria não é diretamente má, mas boa; a tristeza, em troca, é diretamente má.” Ora, já podemos deduzir dessa proposição que a alegria pode ser indiretamente má e que a tristeza pode ser indiretamente boa. Nesse sentido, diz o enunciado da E IV 42: "O contentamento nunca é excessivo, mas sempre bom, enquanto, inversamente, a melancolia é sempre má.” E, finalmente, o enunciado da E IV 43 explicita o que foi deduzido acima: “A excitação pode ser excessiva e ser má; em troca, a dor - à medida que a excitação, ou seja, a alegria, for má - pode ser boa.” Segundo a demonstração da mesma proposição, “a potência desse afeto [excitação] pode ser tanta que supera as outras ações do corpo (pela prop. 6); e que esse afeto permaneça obstinadamente fixo a ele, impedindo, assim, que o corpo seja capaz de ser afetado de muitas outras maneiras.” Dessa maneira, a mente se ocupa somente com uma coisa em vez de aumentar sua potência de pensar com outras coisas. A mente padece quando é levada a pensar em função de uma causa exterior, justamente como explica o primeiro escólio da E IV 37: “a impotência consiste em o homem se deixar conduzir apenas pelas coisas que estão fora dele e em ser determinado por elas a fazer aquilo que o arranjo ordinário das coisas exige e não aquilo que exige a sua própria natureza, considerada em si mesma." Quando o corpo é afetado de diversas maneiras, a mente (ideia do corpo) torna-se, na mesma medida, mais capaz de produzir ideias polivalentes mediante sua relação com as causas 
exteriores. Em contrapartida, a dor pode ser indiretamente boa, se sua potência for capaz de refrear a excitação, de modo que esta então deixe de ser excessiva, tornando o corpo capaz de se afetar de diversas maneiras.

Se a comiseração fosse concebida como um afeto de dor, talvez ela pudesse se tornar indiretamente boa, caso fosse mesmo capaz de refrear um excesso de excitação. Desse modo, a comiseração não seria diretamente um afeto ruim, mas possivelmente bom em alguns casos, como, por exemplo, através de um acontecimento fortuito que levasse o sofrente a compreender a impotência desse afeto, considerando que, quando a mente compreende uma tristeza, esta acaba por se transformar em alegria. Vale lembrar ainda que a dor afeta mais uma parte do corpo que as outras; por isso sua força e duração teriam de ser proporcionalmente menores. Assim, seria menos custoso para o conatus superar a impotência de uma dor que a impotência de uma melancolia, já que esta afeta igualmente todas as partes do corpo e sua força e duração são proporcionalmente maiores. Nesse caso, a melancolia pode ser interpretada como um afeto de morbidez que se coloca no lugar de um obstáculo ao conatus ou esforço pelo qual o homem se esforça em perseverar em seu ser. Segundo o terceiro corolário da E III 27, quando um homem se esforça em livrar outro homem de uma desgraça, ele se esforça para se livrar da tristeza causada pela comiseração, ou seja, pela imitação dos afetos, ele sente a tristeza do outro como se fosse a sua e assim é tomado pelo apetite de destruí-la. Isso basta para explicar, pelo exemplo da comiseração, que o conatus de um corpo jamais o conduziria a uma suposta impotência absoluta ou a seu próprio aniquilamento; isso seria consequência de uma força contrária agindo sobre o homem, uma relação de apatia frente a uma causa exterior contrária. Logo, a comiseração talvez fosse mais atípica, caso fosse concebida mais como melancolia do que como dor. Se a comiseração fosse definida pela dominação da melancolia, esse afeto levaria o homem a um estado de prostração do qual ele dificilmente conseguiria se livrar. De acordo com essa hipótese (meramente ilustrativa), a comiseração não seria outra coisa senão um afeto de tristeza que levaria inevitavelmente à impotência generalizada, o que seria um absurdo, pois nenhum afeto em si mesmo poderia conduzir o homem à impotência ou imperfeição de modo absoluto. Podemos agora compreender o que ocorre com o afeto do contentamento que lhe é contrário. Se esse afeto fosse comum, os homens em geral seriam poucas vezes afetados pela comiseração, uma vez que todas as partes do corpo agiriam em prol de seu próprio aumento 
de potência por longo tempo, com tenacidade e vigor expressivos. Daí a afirmação de Spinoza no escólio da E IV 44:

É mais fácil conceber o contentamento, que eu disse ser bom, do que observá-lo. Com efeito, os afetos pelos quais somos cotidianamente afligidos estão referidos, em geral, a uma parte do corpo que é mais afetada que as outras e, por isso, esses afetos são, em geral, excessivos, e ocupam a mente de tal maneira na consideração de um único objeto que ela não pode pensar em outros.

Diante disso, ainda é necessário analisar os afetos de benevolência e piedade, assim como a ambiguidade contida na definição de benevolência elaborada por Spinoza. Segundo o escólio do terceiro corolário da E III 27, “Essa vontade ou esse apetite de fazer o bem que provém de nossa comiseração para com a coisa à qual queremos fazer o bem, chama-se benevolência, a qual, por isso, nada mais é do que um desejo surgido da comiseração.” Isoladamente considerada, a comiseração é uma tristeza, mas a benevolência dela proveniente é um desejo. Ou seja, a benevolência, segundo essa definição, é um desejo que surge de uma tristeza, mas esse desejo não pode ser ruim em si mesmo. Pois, de acordo com a demonstração da E IV 18, o desejo que surge da tristeza é mais fraco do que o que surge da alegria, pois além de ser diminuída ou refreada pelo próprio afeto de tristeza, sua força deve ser definida exclusivamente pela potência humana. Por outro lado, o desejo que surge da alegria é estimulado ou aumentado pelo próprio afeto de alegria e sua força deve ser definida tanto pela potência humana quanto pela potência da causa exterior. Isso quer dizer então que a benevolência, concebida como desejo que surge da comiseração, não poderia também ser concebida, em outro caso, como desejo que surge da piedade? Mas que distinção haveria entre a benevolência proveniente da comiseração e a benevolência que provém da piedade? De que maneira esses afetos definem o conteúdo prático de suas ações?

Ora, a comiseração e a benevolência não poderiam ser referidas ao mesmo afeto. A causa da comiseração é a tristeza, enquanto a causa da piedade é a alegria. Mas Spinoza só utilizada o termo ‘benevolência’ quando se refere à comiseração, embora empregue o mesmo significado prático (desejo de fazer o bem) quando se refere à piedade. Precisamos então confrontar aquela definição de benevolência ${ }^{4}$ com a de-

4 Escólio do terceiro corolário da E III 27: "Essa vontade ou esse apetite de fazer o bem que provém de nossa comiseração para com a coisa à qual queremos fazer o bem, chama-se benevolência, a qual, por isso, nada mais é do que um desejo surgido da comiseração.” 
finição de piedade: “Quanto ao desejo de fazer o bem, que surge por vivermos sob a condução da razão, chamo de piedade.” (escólio 1, E IV 37). Segundo minha hipótese, elaborada a partir da distinção suscitada por Spinoza, no caso da piedade, o homem seria conduzido pela razão (atividade), e na comiseração, pela paixão (passividade). Ou seja, no caso da piedade, o corpo age, ao passo que, no caso da comiseração, o corpo padece. A benevolência que surge da comiseração é um desejo proveniente da tristeza, enquanto a benevolência que surge da piedade é um desejo que provém da alegria e está referido à razão como afeto de compreensão da necessidade da natureza como embate permanente entre caos e ordem natural do mundo. A razão se constitui através do próprio aumento ou estímulo de potência que define o afeto da alegria. A razão é um afeto ativo, altamente complexo, pelo qual o homem é capaz de explicar outros complexos afetivos. Assim, pode-se definir a razão como uma espécie de afeto inquiridor, que se constitui pela ação de compreender a própria dinâmica dos afetos. Portanto, razão é ação e ação é complexificação dos corpos. E quanto mais complexo é um corpo, tanto maior é sua potência.

Por outro lado, Spinoza apresenta a benevolência do ponto de vista do conteúdo prático da ação (efeito) de acordo com a causa ou afeto que causa a ação de fazer o bem. É pela razão que somos naturalmente inclinados a livrar alguém do sofrimento. Não se trata de uma virtude moral, como a tradição da filosofia moderna tanto se esforçou em defender.

Quanto ao bem que dela [comiseração] se segue [benevolência], a saber, que nos esforçamos por livrar da infelicidade um homem que nos causa comiseração (pelo corol. 3 da prop. 27 da P. 3), desejamos fazê-lo apenas pelo ditame da razão (pela prop. 37), e apenas pelo ditame da razão podemos fazer algo que sabemos, com certeza, ser bom (pela prop. 27). (demonstração, E IV 50)

Nota-se, assim, que o próprio movimento do conatus já elucida os ditames da razão. Quando um homem é afetado pela comiseração, ele imagina a tristeza alheia como sua e se esforça em destruí-la. Mas para o homem que vive sob a condução da razão, a comiseração é inútil, pois diminui ou refreia a potência de agir. Se o tipo "homem livre" age com benevolência e ao mesmo tempo sabe o que está fazendo, isso não ocorreria por obediência a algum dever ou código moral de comportamento, ou ainda, como consequência passiva da imitação dos afetos, mas porque essa ação lhe é de suprema utilidade, na medida em que, ao livrá-lo de um sofrimento, aumenta ou estimula sua potência de agir. Tudo indica que, quando um homem presta uma ajuda 
sob a condução da razão, assim o faz de modo a promover um encontro "egoísta" (um egoísmo sem ego) entre a sua natureza e a natureza do outro. E se, em vez do sofrimento, esse encontro é promovido pela alegria, então disso se segue um afeto de alegria compartilhada: uma alegria ainda mais potente, na medida em que aumenta ou estimula a potência de agir de dois ou mais corpos humanos. Após definir a comiseração no escólio da E III 22, Spinoza afirma o seguinte: "Não sei, por outro lado, como denominar a alegria originada da felicidade alheia." Diante disso, passo a chamar esse afeto de alegria compartilhada. Nesse sentido, diz o escólio da E IV 50,

Quem compreendeu corretamente que tudo se segue da necessidade da natureza divina e se faz segundo as leis e regras eternas da natureza, não [...] sentirá comiseração por ninguém, mas se esforçará, tanto quanto permita a virtude humana, por fazer, como comumente se diz, o bem, e por se alegrar. Além disso, quem é facilmente tocado pelo afeto da comiseração e se comove com a infelicidade ou as lágrimas alheias, faz, muitas vezes, algo de que, depois, se arrepende, tanto porque, pelo afeto, nada fazemos que saibamos, com certeza, ser bom, quanto porque somos facilmente enganados por falsas lágrimas. [...] Com efeito, quem não é levado nem pela razão, nem pela comiseração, a ajudar os outros, é, apropriadamente, chamado de inumano, pois (pela prop. 27 da P. 3) parece não ter semelhança com o homem.

Portanto, uma coisa é a comiseração considerada em si mesma, outra coisa é o bem que dela se segue (benevolência). Por isso, proponho distinguir a benevolência segundo sua causa e não segundo seu efeito ou conteúdo prático da ação. Uma coisa é a benevolência proveniente da comiseração, outra coisa é a benevolência que provém da piedade: a primeira é uma ação derivada da tristeza, enquanto a segunda, uma ação derivada da alegria. Ou seja, quando age por comiseração, o homem é conduzido pela paixão, e quando age pela piedade, é conduzido pelos ditames da razão. Enquanto a piedade promove a partilha da alegria, a comiseração promove a partilha da tristeza (um comiserar-se com). Movido pela comiseração, o homem até pode livrar-se de sua tristeza, mas dificilmente poderá se afetar de alegria, sem considerar que, nesse caso, seria pouco provável a coexistência de um excesso de excitação para o qual a dor pudesse ser útil.

Se Spinoza chama de comiseração a imitação dos afetos referida à tristeza, chamo de piedade a imitação dos afetos referida à alegria, precisamente porque, aí nesse caso, somos capazes de compreender os afetos que imitamos. No escólio da E IV 18, 
Spinoza destaca que existem afetos que estão de acordo com os ditames da razão, enquanto existem outros que lhe são contrários. Seguir os ditames da razão significa agir de acordo com sua própria natureza. E nesse sentido, o conatus diz respeito ao esforço pelo qual o homem se esforça em conservar seu ser pelas "leis da natureza": por isso, Spinoza remete à razão a palavra “ditame”. Seguir os ditames da razão significa, então, afirmar o próprio conatus, pois a razão "não exige nada que seja contra a natureza”, e esta "exige que cada qual ame a si próprio", "que busque o que lhe seja útil” (escólio, E IV 18). Os ditames da razão exigem, enfim, que o homem se esforce por ser afetado de alegria, que deseje tudo aquilo que aumente ou estimule sua potência de agir, pois esse desejo será estimulado ou aumentado pelo próprio afeto de alegria e sua força será definida tanto pela potência humana quanto pela potência da causa exterior, como diz a demonstração da E IV 18. Isso significa que o homem que vive sob a condução da razão afirma seu próprio conatus precisamente quando, na medida em que age diante de causas que lhe são exteriores, sempre busca extrair das relações com o ambiente externo o que lhe é de máxima utilidade, o que pode aumentar ou estimular sua potência de existir. Disso se segue, portanto, que não há nada mais útil para o homem do que aquilo que concorda com sua natureza. É o que ilustra o primeiro corolário da E IV 35: "Não há, na natureza das coisas, nenhuma coisa singular que seja mais útil ao homem do que um homem que vive sob a condução da razão.”

\section{CONCLUSÃo}

A piedade expressaria uma concórdia entre a natureza dos homens conduzidos pelos ditames da razão. Buscar o que lhe é útil define a prática da piedade em Spinoza, diferentemente do que defende a tradição da filosofia moderna que condena o amor a si mesmo. Como nos diz o enunciado da E IV 35, "Apenas à medida que vivem sob a condução da razão, os homens concordam, sempre e necessariamente, em natureza”. Por conseguinte, “os homens que se regem pela razão, isto é, os homens que buscam, sob a condução da razão, o que lhes é útil, nada apetecem para si que não desejem também para os outros” (escólio, E IV 18). Nesse sentido, continua Spinoza, “É quando cada homem busca o que é de máxima utilidade para si, que são, todos, então, de máxima utilidade uns para com os outros" (idem). Eis o sentido político da concórdia promovida na medida em que cada um busca o que é de máxima utilidade para si mesmo e ao mesmo tempo age de modo a abrir possibilidades de concordar com outros corpos 
mediante o antagonismo consequente da associação entre naturezas afins; pois não haveria um elo previamente dado entre naturezas do mesmo gênero: o que precede a semelhança é a diferença e o que disso se segue é uma associação por afinidades. Portanto, o homem que age frequentemente afetado de comiseração, em alguma medida deixa de buscar o que lhe é de máxima utilidade, e por não observar seus próprios apetites, acaba por se tornar menos capaz de agir piedosamente ou segundo os ditames da razão. Concebida segundo o conteúdo prático da ação, a benevolência pode ser conduzida tanto pela razão (piedade) quanto pela comiseração. Nesse último caso, o corpo humano padece e naturalmente luta a todo custo, enquanto houver vida, para livrar-se de uma paixão.

\section{REFERÊNCIA BIBLIOGRÁFICA}

SPINOZA, Benedictus de. Ética. Tradução e notas de Tomaz Tadeu. 2. ed. Belo Horizonte: Autêntica, 2008. 